\title{
The neuropsychological profile of professional action video game players
}

\author{
Julie Justine Benoit ${ }^{\text {Corresp., } 1,2}{ }^{\text {, Eugenie Roudaia }}{ }^{3}$, Taylor Johnson $^{4}$, Trevor Love $^{4}$, Jocelyn Faubert ${ }^{2}$ \\ 1 Department of Psychology, Université de Montréal, Montréal, Québec, Canada \\ 2 Faubert Lab, École d'Optométrie, Université de Montréal, Montréal, Québec, Canada \\ 3 Rotman Research Institute, Toronto, Ontario, Canada \\ 4 Infinite Esports and Entertainment, Frisco, Texas, United-States \\ Corresponding Author: Julie Justine Benoit \\ Email address: juliejustine_benoit@hotmail.com
}

In the past 20 years, there has been growing research interest in the association between video games and cognition. Although many studies have found that video game players are better than non-players in multiple cognitive domains, other studies failed to replicate these results. Until now, the vast majority of studies defined video game players based on the number of hours an individual spent playing video games, with relatively few studies focusing on video game expertise using performance criteria. In the current study, we sought to examine whether individuals who play video games at a professional level in the esports industry differ from amateur video game players in their cognitive and learning abilities.

We assessed 14 video game players who play in a competitive league (Professional) and 16 casual video game players (Amateur) on set of standard neuropsychological tests evaluating processing speed, attention, memory, executive functions, and manual dexterity. We also examined participants' ability to improve performance on a dynamic visual attention task that required tracking multiple objects in threedimensions (3D-MOT) over five sessions.

Professional players showed the largest performance advantage relative to Amateur players in a test of visual spatial memory (Spatial Span), with more modest benefits in a test of selective and sustained attention (d2 Test of Attention), and test of auditory memory (Digit Span). Professional players also showed better speed thresholds in the 3D-MOT task overall, but the rate of improvement with training did not differ in the two groups. Future longitudinal studies of elite video game experts are required to determine whether the observed performance benefits of professional gamers may be due to their greater engagement in video game play, or due to pre-existing differences that promote achievement of high performance in action video games. 
1 The neuropsychological profile of professional action video game players

2

3 Julie Justine Benoit ${ }^{1,4}$, Eugenie Roudaia ${ }^{2}$, Taylor Johnson ${ }^{3}$, Trevor Love ${ }^{3}$, Jocelyn Faubert ${ }^{4}$

$6 \quad{ }^{1}$ Department of Psychology, Université de Montréal, Québec, Canada

$7 \quad 2$ Rotman Research Institute, Toronto, Ontario, Canada

$8 \quad 3$ Infinite Esports and Entertainment, Texas, United States

$9{ }^{4}$ Faubert Lab, École d'Optométrie, Université de Montréal, Québec, Canada

14 Corresponding author:

15 Julie Justine Benoit ${ }^{1}$

16 Email: juliejustine_benoit@hotmail.com

17

18 


\section{Abstract}

20 In the past 20 years, there has been growing research interest in the association between video

21 games and cognition. Although many studies have found that video game players are better than

22 non-players in multiple cognitive domains, other studies have failed to replicate these results.

23 Until now, the vast majority of studies defined video game players based on the amount of time

24 they spent playing video games, with relatively few studies focusing on the players' video game

25 expertise using performance criteria. In the current study, we sought to examine the cognitive

26 and learning abilities of video game players who achieved a professional level in the eSports

27 industry relative to amateur video game players. We tested 14 video game players who play in a

28 competitive league (Professional) and 16 casual video game players (Amateur) on a series of

29 standard neuropsychological tests evaluating processing speed, attention, memory, executive

30 functions, and manual dexterity. We also examined participants' ability to improve performance

31 on a dynamic visual attention task that required participants to track a subset of randomly

32 moving objects in a three-dimensional space (3D-MOT) over five sessions. Professional players

33 showed the largest performance advantage relative to Amateur players in a test of visual spatial

34 memory (Spatial Span), with more modest benefits in a test of selective and sustained attention

35 (d2 Test of Attention), and a test of auditory memory (Digit Span). Professional players also

36 showed better performance in the 3D-MOT task overall, but the rate of improvement with

37 training did not differ between both groups. Longitudinal studies of video game players are

38 needed to determine to what extent the better performance in our Professional players is due to

39 their greater engagement in video game play or to pre-existing cognitive traits that promote

40 attainment of high performance levels in action video games. 


\section{Introduction}

42 There were more than two billion video gamers worldwide in 2016 and this number is projected

43 to increase to 2.7 billion by 2021 (Statista, 2020). In the United States, the gamer population

44 consists of more than 150 million individuals, representing a 17.7 billion dollar market (Bediou

45 et al., 2018; SpillGames, 2013; Statista, 2017). There is a wide variety of video game genres,

46 including action, real-time strategy, fighting, adventure, role playing, and racing games. Action

47 video games (AVGs) such as Call of Duty, Grand Theft Auto, Halo, Fallout 4, Fortnite, and

48 Overwatch, are among the most popular types of video games in the United States (Statista,

49 2019). More recently, we have witnessed the emergence of the eSports industry, in which video

50 gamers compete individually or in teams in national and international competitions. More than

51117 schools in the United States offer competitive eSports programs and many professional

52 leagues are experiencing growing audiences and revenues (NACE, 2020; Newzoo, 2020).

54 The rise in popularity of video games in the last 20 years has led to a surge of research

55 examining their impact on the mind and brain, with a special focus on AVGs. Although AVGs

56 differ from one another, they all share four characteristics: a fast pace (moving objects, time

57 constraints), a high perceptual load, a high degree of distraction, and a requirement for constant

58 switching between focused and distributed states of attention (Bediou et al., 2018). AVGs are

59 also highly engaging and intrinsically motivating activities, making them attractive and popular

60 (Powers \& Brooks, 2014). First-person shooter (FPS) games, in which the player has an

61 egocentric view through his or her avatar's eyes, have been the focus of many studies, as they

62 were suspected to be the most likely genre of AVGs to influence cognition due to their high

63 engagement of sensory, perceptual, and cognitive functions (Spence \& Feng, 2010). Although 
64 AVGs are the most studied, other types of games, like real-time strategy games, have also been

65 shown to affect cognition (Glass, Maddox, \& Love, 2013). Cross-sectional studies comparing

66 habitual players of AVGs and non-players have reported that, as a group, habitual players of

67 AVGs perform better than non-players in multiple cognitive domains, including selective

68 attention (Castel, Pratt, \& Drummond, 2005; Dye, Green, \& Bavelier, 2009; Green \& Bavelier,

69 2003; Green \& Bavelier, 2006), speed of processing (Castel et al., 2005; Dye et al., 2009),

70 executive functions (Andrews \& Murphy, 2006; Colzato, Van Leeuwen, Van Den Wildenberg,

$71 \&$ Hommel, 2010) and working memory (Colzato, van den Wildenberg, Zmigrod, \& Hommel,

72 2013). These cross-sectional, observational studies have been reinforced by several intervention

73 studies that have demonstrated an improvement in the same cognitive domains in non-players

74 following training with AVGs (Feng, Spence, \& Pratt, 2007; Powers \& Brooks, 2014; Spence,

75 Yu, Feng, \& Marshman, 2009). A recent meta-analysis of 82 studies focusing on AVGs

76 concluded that AVGs are associated with improved cognitive function in general, with the most

77 robust effects seen in the domains of spatial cognition, top-down attention, and perception;

78 medium effects seen in multitasking and task-switching; and only weak effects seen in inhibition

79 and verbal cognition (Bediou et al., 2018). Nevertheless, several other studies have failed to find

80 benefits of video gaming using similar methodologies (Cain, Landau, \& Shimamura, 2012; Irons,

81 Remington, \& McLean, 2011; Murphy \& Spencer, 2009).

82

83 The vast majority of studies examining the effects of AVGs on perceptual and cognitive function

84 studied video game players who were defined based on a criterion amount of time they spent

85 engaging in video game play over the past 6 - 12 months, with only a few studies also

86 characterizing players based on their level of performance in a game. Latham, Patston and 
87 Tippett (2013) argued that the lack of consideration of individual differences in the level of

88 performance in video games, in addition to experience, likely contributes to the heterogeneous

89 results in the literature and limits our understanding of video game expertise. One category of

90 experts that excels relative to others are elites. In the broadest sense, experts can be described as

91 individuals who acquire knowledge or abilities in a specific domain such as a profession, hobby,

92 sport, or game, by devoting a substantial amount of time to that activity (Chi, Glaser, \& Farr,

93 2014; Ericsson \& Towne, 2013; Farrington-Darby \& Wilson, 2006). Elites are experts who

94 achieve a high level of performance in their domain relative to others. In the context of sports for

95 example, athletes who play in professional leagues or who rank highly in international

96 competitions are considered elites (Swann, Moran, \& Piggott, 2015). In video games, elites are

97 those players who consistently achieve high rankings or who are selected to participate in

98 professional leagues. While practice is necessary to achieve high levels of performance, the

99 amount of practice alone is not sufficient, as an individual can practice a lot and acquire

100 knowledge in a specific area without ever becoming an elite (Ericsson \& Towne, 2013).

102 Research on expertise has sought to understand whether there are certain characteristics that

103 enable individuals to achieve high levels of performance in various domains (Chi et al., 2014). In

104 sports, research has focused on evaluating perceptual-cognitive capacities, which refer to the

105 ability to identify and amass information to combine with actual knowledge in order to select and

106 execute the appropriate response (Chi et al., 2014; Mann et al., 2007). The ability to extract

107 information rapidly is a crucial element of high-level competitive sports, as athletes must direct

108 their attention to the relevant aspects of the wide and dense visual scene in order to make fast

109 decisions (Mann et al., 2007). A meta-analysis of athletes across various sports reported that elite 
110 athletes are indeed better able to extract pertinent information in the visual scene in the context

111 of their sport, while also showing a different pattern of eye movements and visual search

112 strategies relative to non-elite athletes (Mann, Williams, Ward, \& Janelle, 2007). Perceptual-

113 cognitive capacities may also be important in videogaming, where a player must also select and

114 extract relevant information to keep track of his or her enemies while anticipating their actions

115 and deciding the best strategy to reach his or her objective.

116

117 More broadly, it has been suggested that individuals who achieve high levels of expertise also

118 show enhanced performance across a wide range of core cognitive or perceptual domains in

119 general, outside the specific context of their expertise. To continue with the example of sports,

120 several recent studies have found that elite athletes outperform non-athletes in cognitive tests

121 evaluating attention, multitasking, working memory, and processing speed, with group effects

122 ranging from small to medium effect sizes (Faubert, 2013; Scharfen \& Memmert, 2019;

123 Vaughan \& Laborde, 2020; Voss, Kramer, Basak, Prakash, \& Roberts, 2010). Professional

124 athletes also showed faster improvement in performance on a three-dimensional multiple-object-

125 tracking task (3D-MOT) as a function of training, compared to high-level amateurs and to non-

126 athletes (Faubert, 2013; Faubert \& Sidebottom, 2012). The 3D-MOT task determines the speed

127 at which the participant can track a subset of identical moving objects in a three-dimensional

128 space over several seconds. The maximum speed at which a given number of targets can be

129 tracked shows large individual variability, improves with training (Faubert, 2013; Legault,

130 Allard, \& Faubert, 2013; Parsons et al., 2016; Tullo, Faubert, \& Bertone, 2018), and is associated

131 with better decision making in sports (Romeas, Guldner, \& Faubert, 2016). The finding that the

132 improvement in 3D-MOT performance with practice was greater in professionals may point to 
133 generally enhanced learning abilities within the context of any dynamic visual scene. In sum, the

134 studies above suggest that the outstanding performance achieved by elite athletes may be

135 associated with enhanced abilities in a range of cognitive domains, including attention,

136 processing speed, working memory, and learning abilities.

138 To our knowledge, no existing studies have examined whether professional action video game

139 players also exhibit enhanced cognitive abilities relative to amateur players. While growing

140 evidence supports a link between playing action video games and cognitive ability (Bediou et al.,

141 2018), further research is needed to better understand the nature of this association. Studying

142 cognitive abilities of professional video gamers can shed more light on this relationship, by

143 providing clues as to how expertise is developed, the mechanisms at play, and how best to

144 support and improve it (Farrington-Darby \& Wilson, 2006). Specifically, we can address the

145 following question: does the outstanding performance of professional video game players stem

146 from enhanced cognitive abilities in certain domains, or is it largely due to a greater expertise

147 within the context of the game?

148

149 To address this gap, this study aimed to characterize the cognitive and learning abilities of high-

150 performance action video game players recruited amongst the Houston Outlaws, a professional

151 team in the Overwatch league ${ }^{\mathrm{TM}}$. We used a selection of standardized neuropsychological tests to

152 evaluate cognitive abilities, and trained participants on the 3D-MOT task to assess their abilities

153 to learn a novel, dynamic perceptual-cognitive task. We hypothesized that professional players

154 would perform better than amateur players on neuropsychological tasks that evaluate attention,

155 processing speed, executive functions, working memory, and visuo-spatial manipulation, as these 
156 aspects of cognition have been found to be more developed in habitual video game players when

157 compared with non-players (Bediou et al., 2018). We also hypothesized that professional players

158 would show faster learning rates on 3D-MOT compared with amateur players, as was observed

159 with expert athletes (Faubert, 2013).

160

161 Materials \& Methods

\section{Participants}

163 The experimental protocol was evaluated and approved by the Comité d'Éthique de la Recherche 164 en Santé of Université de Montréal (18-009-CERES-D). Fourteen participants (all men, right-

165 handed) were recruited amongst competitive players in the Overwatch League ${ }^{\mathrm{TM}}$ for the Houston

166 Outlaws (Professional group). These participants are considered elite video gamers, because they

167 have achieved the necessary performance level to enter a professional league. They reported

168 daily FPS video game usage in the last 6 months and were ranked as Grandmaster or Top

169 500/Pro in the game. As a comparison group, we recruited habitual video game players (Amateur

170 group) through online advertisements targeted at undergraduate students at the Université de

171 Montréal. Knowing that the video game category and type may be important influencing factors

172 (Dobrowolski, Hanusz, Sobczyk, Skorko, \& Wiatrow, 2015), participants in the Amateur group

173 needed have played more than 5 hours per week of FPS during the last 6 months. They also

174 could not have previously participated in organized video game competitions or played more

175 than 20 hours per week in the past 6 months. This exclusion criterion was used to ensure that the

176 Amateur group was homogeneous and similar to previous studies in the range of hours of game

177 play per week (Bavelier \& Green, 2003, 2005, 2006; Karle, Watter \& Shedden, 2010; Colzato,

178 van den Wildenberg, Zmigrod \& Hommel, 2013). A total of 20 participants (3 left-handed, 4 
179 female) were enrolled in the Amateur group. Two participants were then excluded for playing

180 more than $20 \mathrm{~h}$ per week or for having taken part in competitions, and two more were excluded

181 due to inadequate testing environments, resulting in a sample of 16 participants in the Amateur

182 group. Demographic and video game experience characteristics of the two groups are

183 summarized in Table 1. All participants were screened for depressive symptoms using the Beck

184 Depression Inventory II (BDI-II) (Wang \& Gorenstein, 2013); no participants were excluded

185 based on their BDI-II scores (exclusion $>20$ ). Participants had normal or corrected-to-normal

186 vision and were free of visual, neurological, musculoskeletal, cardiovascular and vestibular

187 impairments, as assessed by self-report. Handedness was also self-reported. All participants gave

188 their verbal and written informed consent to participate after receiving verbal and written

189 information about the study. They were not paid for their participation.

190

\section{Neuropsychological measures}

192 Table 2 summarizes the eight neuropsychological tests that were used in this study.

193 The d2 Test of Attention (Brickenkam \& Zillmer, 1998) was selected to evaluate selective and

194 sustained attention skills, as well as speed of processing. In this test, participants are presented

195 with a sheet of paper containing 14 lines of 47 items each. The items are either a "p" or a "d"

196 with one to four dashes placed alone or in pairs below and above the letter. Participants are given

19720 seconds per line to cross out all the items containing a " $d$ " with two dashes. The outcome

198 measures include the total number of items processed (TN), percent of errors of omission and

199 commission $(\% \mathrm{E})$, number of correct items (TN-E), concentration performance (CP), and

200 variability in performance across lines (fluctuation ratio, FR). 
201 The WAIS-IV Coding test was selected to evaluate visual processing speed (Wechsler, 2011). In

202 this task, participants are required to code a series of numbers using symbols shown on a key at

203 the top of the page, similar to the Digit Symbol Substitution Test. The total number of items that

204 are coded in two minutes is recorded.

205 The WAIS-IV Visual Puzzles was selected to evaluate visual reasoning and the ability to

206 manipulate visual information (Wechsler, 2011). This task requires the participant to decide

207 which three of six puzzle pieces combine together to reconstruct a larger puzzle within a limited

208 time. The number of successfully completed puzzles is scored.

209 The WAIS-IV Digit Span test (Wechsler, 2011) was selected to evaluate auditory working

210 memory (aWM) and short-term memory (aSTM). The test requires participants to listen to a

211 series of digits that are read out loud and to recite them back in the same order (Forward subtest),

212 in backwards order (Backward subtest), or in increasing numerical order (Sequencing subtest).

213 The total number of correctly reported sequences is scored (Weiss, Saklofske, Coalson, \&

214 Raiford, 2010).

215 The Wechsler Memory Scale-III (WMS-III) Spatial Span test (Kessels, van den Berg, Ruis, \&

216 Brands, 2008) was selected to evaluate visual working memory (vWM) and visual short-term

217 memory (vSTM). In this test, participants are shown nine cubes placed randomly on a board. The

218 examiner taps a number of cubes in a sequence and participants have to reproduce this sequence

219 either in the order presented (Forward subtest) or in backwards order (Backward subtest). The

220 total number of successful sequences on each subtest is scored.

221 Two tests from the Delis Kaplan Executive Function System (D-KEFS) were selected to evaluate

222 executive function (Delis, Kaplan, Kramer, Delis, \& Kramer, 2001). The D-KEFS Tower test

223 evaluates problem solving and planning. The task requires moving five disks across three pegs to 
224 build a tower in the fewest number of moves possible. Performance is scored by combining the

225 total achievement score, which is the sum of achievement points for all the administered items,

226 and the move accuracy ratio score, which assesses the efficiency with which the participant

227 constructed the towers.

228 The D-KEFS Colour-Word Interference test is a version of the Stroop test that evaluates

229 inhibition and cognitive flexibility. In the Inhibition condition, participants are required to name

230 the colour of the ink of a series of words that spell a name of a different colour. In the Flexibility

231 condition, participants are required to read the words that are outlined by a rectangle, but to name

232 the ink colour of the other words that are not outlined. The time required to complete a set of

233 words is recorded (Strauss, Sherman, \& Spreen, 2006).

234 Finally, the Grooved Pegboard test (Lafayette Model 32025) was selected to evaluate hand-eye

235 coordination and dexterity (Strauss et al., 2006). This test requires participants to pick up small

236 metal pegs that have a key on one end and insert them into randomly oriented slots on the board

237 by rotating the pegs into the correct position. The test is performed with each hand separately

238 and the time required to insert twenty-five pegs into the slots is recorded.

239

240 Three-Dimensional Multiple Objects Tracking (3D-MOT)

241 The 3D-MOT sessions were conducted in a quiet room using a fully immersive environment

242 with a Fove ${ }^{\mathrm{TM}}$ virtual reality device. The head-mounted display had a resolution of 2560 x 1440

243 pixels and covered a maximal visual field of 45 degrees. The 3D-MOT task was delivered using

244 a Dell Inspiration 15700 Gaming Series computer.

245 The 3D-MOT was developed as an optimal training procedure to improve mental abilities critical

246 for processing dynamic scenes, such as those encountered during sports or video gaming 
247 (Faubert \& Sidebottom, 2012). The procedure adapts the well-known multiple object tracking

248 task (Pylyshyn \& Storm, 1988), in which participants track several moving targets among

249 distractors, by expanding it to cover a large span of the visual field in three dimensions using

250 stereoscopic presentation, and by varying the speed of the moving objects on every trial to

251 determine a speed threshold (Faubert \& Sidebottom, 2012).

252

253 During the 3D-MOT task (Figure 1), participants were required to track four of eight spheres that

254 moved within a cube delineated by light grey walls with their attention only, without eye

255 movements. A green fixation square was presented in the center of the cube and participants

256 were asked to maintain fixation on the square throughout the tracking phase. Each trial began

257 with the presentation of all eight yellow spheres positioned at random locations within the cube

258 for two seconds. The four target spheres were then highlighted by changing to a red colour with a

259 white halo for two seconds. Once the targets returned to the yellow colour for once second, all

260 eight spheres began to move along linear paths in random directions within the cube, changing

261 directions when colliding with each other or with the walls. After eight seconds, the spheres

262 stopped moving and were labeled with numbers 1 through 8 . The participant was then prompted

263 to verbally identify the target spheres. After their choice was entered, the correct targets were

264 revealed for two seconds to provide the participant feedback. The next trial began shortly

265 afterwards. The speed of all the spheres varied across trials according to a one-up, one-down

266 staircase procedure to estimate the speed required to track all four targets correctly $50 \%$ of the

267 time (Levitt, 1971). The speed increased by $0.05 \log$ units if the participant correctly identified

268 all targets and decreased by the same amount if the participant missed at least one target. The

269 staircase procedure was interrupted after 20 trials and the speed threshold was estimated using 
270 the geometric mean of the speeds for the last four reversals. A complete staircase procedure

271 lasted approximately eight minutes.

272

273 Figure 1 | Five stages of a trial in the 3D-MOT task. a) Presentation phase, in which eight

274 spheres appear in random locations in a 3D space. b) Indexing phase, in which four spheres are

275 cued as targets using a colour change for two seconds. c) Movement phase, in which all spheres

276 move for eight seconds in random directions, crisscrossing and bouncing off of each other and

277 the walls of the 3D space. The participant is asked to keep track of the targets, while fixating at

278 the central fixation point. d) Identification phase, in which the immobilized spheres are

279 numbered $1-8$ and the participant is asked to identify the four targets. e) Feedback phase, in

280 which the target spheres are highlighted in red and a star is shown if all four targets were selected 281 correctly.

282

283 Procedure

284 Participants in the Professional group were tested at their headquarters located in Burbank,

285 California, and in Frisco, Texas. Participants in the Amateur group were tested in their homes in

286 Montreal. The same experimenter administered all the tests. In the first visit, participants first

287 completed a demographics and video game experience questionnaire. Then, participants

288 completed the paper and pencil neuropsychological tests in their preferred language (English or

289 French), which lasted approximately one hour. Participants then completed the 3D-MOT task

290 three times. Subsequent 3D-MOT training sessions were completed in four additional sessions,

291 which were spaced apart by a minimum of 6 hours and a maximum of 72 hours. 


\section{Analysis}

294 Two participants in the Professional group did not have high proficiency in English or French, so

295 they were not tested on the Digit Span and Colour Word Interference tests, since performance in

296 these tests depends on language proficiency. One of these participants also did not complete the

297 Tower test, due to difficulties with understanding instructions. Data for the 3D-MOT training

298 sessions were available for 27 of 30 participants, because three participants in the Amateur group

299 did not complete the five 3D-MOT sessions due to travel restrictions, so their data were excluded

300 from these analyses. Additionally, data from 17 out of 405 blocks across seven participants were

301 missing due to a technical error and were treated as missing at random.

302

303 Statistical analyses were performed in SPSS and in the statistical computing environment R (R

304 Core Team, 2015). First, we compared performance on all the neuropsychological measures in

305 the two groups using independent Welch's t-tests, as the variance in the two groups was unequal

306 for some outcome measures (e.g., Spatial Span total score, Levene's test $\mathrm{p}<0.01$ ). Hedges' $g$

307 was calculated to provide a measure of effect size using the effsize package in R (Torchiano,

308 2016). To evaluate global group differences in neuropsychological measures and to compare the

309 contribution of different outcome measures to the group difference, we conducted a descriptive

310 discriminant analysis (Brown \& Wicker, 2000; Smith, Lamb, \& Henson, 2020). Additionally,

311 bivariate Spearman's correlations were calculated to examine associations among

312 neuropsychological outcome measures.

313

314 To examine the effects of learning on speed thresholds in both groups, we conducted a linear

315 mixed effects analysis using the lme4, pbkrtest, and lmerTest packages in R (Baayen, Davidson, 
316 \& Bates, 2008; Bates et al., 2015; Kuznetsova, Brockhoff, \& Christensen, 2014; Luke, 2017;

317 Team, 2018). The model's outcome variable was the speed threshold, with fixed effects of group,

318 the logarithm of the block number, and their interaction. As random effects, we fit a maximal

319 random effects structure that included by-subject intercepts and by-subject slopes for block

320 (lmer(speed $\sim$ Group * $\log 2($ block $)+(1+\log 2($ block $) \mid$ subject $))$. This analysis is equivalent to

321 fitting a logarithmic learning curve separately for each participant and then evaluating the effect

322 of group on overall speed thresholds and learning rate. P-values for fixed effects were obtained

323 using F-tests with the Kenward-Roger approximation for degrees of freedom (Halekoh \&

324 Højsgaard, 2014).

\section{Results}

326 Table 1 summarises the demographic information and video game experience of participants in

327 the groups. The two groups were well matched in age (Professionals: $\mathrm{M}=23.66, \mathrm{SD}=2.44$,

328 Amateurs: $\mathrm{M}=25.31, \mathrm{SD}=3.77, \mathrm{t}(25.9)=-1.44, \mathrm{p}=0.16)$ and in the average age at which

329 participants started playing video games (Professionals: $\mathrm{M}=6.93, \mathrm{SD}=2.81$, Amateurs: $\mathrm{M}=$

$3306.75, \mathrm{SD}=2.62, \mathrm{t}(26.8)=0.18, \mathrm{p}=0.86)$. Participants in the Professional group devoted

331 approximately five times more time to FPS games than those in the Amateur group in the last six

332 months (Professionals: $\mathrm{M}=55.79 \mathrm{~h}, \mathrm{SD}=16.72$, Amateurs: $\mathrm{M}=9.47 \mathrm{~h}, \mathrm{SD}=3.48, \mathrm{t}(14)=$

$33310.18, \mathrm{p}<0.001)$. There was no evidence for any differences in depression symptoms between

334 both groups (Professionals: $\mathrm{M}=6.85, \mathrm{SD}=5.27$, Amateurs: $\mathrm{M}=4.93, \mathrm{SD}=4.62, \mathrm{t}(24.1)=1.01$, $335 \mathrm{p}=0.32)$.

336

337 Neuropsychological assessments 
338 Figure 2 shows the outcome measures from the eight neuropsychological tests for the two

339 groups. Table 3 presents their summary statistics and the results of univariate, between-group

340 statistical analyses for each measure.

341

342

343

344

345

346

347

348

349

350

351

352

353

354

355

356

357

358

359

360

56

Figure $2 \mid$ Results of neuropsychological tests. Large symbols show the mean group scores and small symbols show individual participant data for the Amateur (black circles) and Professional (red triangles) groups. Error bars represent $1 \mathrm{SD}$ of the mean. The dashed lines represent the maximum score possible for each variable.

In the $\mathrm{d} 2$ Test of Attention, Professional players processed, on average, a greater number of stimuli than those in the Amateur group (TN: $\mathrm{t}(28)=2.41, p=0.02, g=0.85$ ), while maintaining a similar error rate $(E \%: \mathrm{t}(27.3)=0.70, \mathrm{p}=0.49, \mathrm{~g}=0.25)$. When accounting for the error rate, Professional players processed a greater number of stimuli correctly (TN-E: $\mathrm{t}(28)=$ $2.3 ; \mathrm{p}=0.03 ; g=0.81)$, but their Concentration Performance score did not differ significantly from the Amateur group $(\mathrm{CP}: \mathrm{t}(26.4)=1.31 ; \mathrm{p}=0.20 ; \mathrm{g}=0.47)$. The Fluctuation Rate, which measures the consistency of performance throughout the task, was lower in the Professional group (FR: $\mathrm{t}(28)=-2,14 ; \mathrm{p}=0.04 ; g=-0.75)$, indicating better sustained attention.

In the WAIS-IV Spatial Span task, the Professional group showed better performance than the Amateurs on the Total score $(\mathrm{t}(25.5)=3.52, \mathrm{p}<0.001, g=1.27)$, with a large effect size.

Analyzing each subscale separately revealed a large, reliable effect in the Forward subscale, $(\mathrm{t}(28)=3.85 ; \mathrm{p}=0.001, g=1.36)$, but no reliable difference in the Backward subscale $(\mathrm{t}(24.4)=$ 
361 1.92, $\mathrm{p}=0.07, g=0.7)$. In the WAIS-IV Digit Span task, the Professional group also showed

362 better performance on the Total score $(\mathrm{t}(23)=2.20 ; \mathrm{p}=0.04, g=0.82)$, with a smaller effect size

363 than in the Spatial Span test. Scores for the Digit Span Forward, Backward, and Sequencing

364 subscales were not reliably different in the two groups ( $p=0.06,0.11,0.13$, respectively).

365

366 In the WAIS-IV Coding test, the average score in the Professional group was numerically higher

367 than that of the Amateur group, but this group difference was not reliable $(\mathrm{t}(26)=1.54, p=0.14$,

$368 g=0.55)$. There was no evidence for a difference in performance between the two groups on tests

369 of executive function, D-KEFS Towers ( $\mathrm{ps}>0.08)$ and D-KEFS Colour-Word Interference (ps >

370 0.36), nor on the Visual Puzzles test $(\mathrm{ps}=0.44)$, which evaluates perceptual reasoning. There

371 was also no evidence for any difference between groups in the Grooved Pegboard test (ps

$372>0.17$ ), which evaluates hand-eye coordination and manual dexterity.

373

374 Next, we used a multivariate analysis approach to probe for global differences between the two

375 groups across all neuropsychological assessments. To ward against multicollinearity, we selected

376 one measure per task and conducted a descriptive discriminant analysis (DDA; Smith et al.,

377 2020) on this subset of outcome measures, The measures included were d2 TN-E, Spatial Span

378 Total, Digit Span Total, Grooved Peg for the dominant hand, Color-Word Inhibition score, and

379 total scores for Coding, Visual Puzzles, and Towers. The largest bivariate correlation across

380 these measures was -0.55 , indicating that the variables were not multicollinear. The DDA

381 analysis calculates a linear composite of the outcome variables that best separates the two

382 groups. The canonical correlation, $\mathrm{R}_{\mathrm{c}}$, between the composite and Group was 0.67 , with a

383 corresponding $R_{\mathrm{c}}^{2}=0.45$, which is the variance accounted for Group in the composite scores. 
384 This difference was not statistically significant, Wilk's $\Lambda=0.54, \mathrm{~F}(8,19)=1.97, \mathrm{p}=0.11$.

385 Examining the standardized discriminant function coefficients revealed that the Spatial Span

386 Total score made the largest contribution to the composite score, with a coefficient of -0.29 and

$387 \mathrm{r}^{2}=0.62$. Table 4 provides the full results of this analysis.

388

389 3D-MOT training

390 Figure 3 shows the average speed thresholds for tracking four targets in the 3D-MOT task as a

391 function of block number for each group. As can be seen, the Professional group showed higher

392 thresholds overall than the Amateur group, indicating better ability to track multiple targets

393 among distractors. Thresholds in both groups increased as a function of block number, reflecting

394 improvements in task performance as a function of training, with a similar rate of improvement

395 in both groups. These observations were confirmed by a linear mixed effects analysis (see Table

396 5), which revealed a main effect of Group, $\mathrm{F}(1,24.78)=5.54, \mathrm{p}=0.03$, with the Professional

397 group having higher thresholds, $\beta=0.28,95 \% \mathrm{CI}[0.05,0.52]$. There was also a main effect of

398 block, $\mathrm{F}(1,24.78)=76.97, \mathrm{p}<0.001$, with thresholds increasing by $\beta=0.14,95 \% \mathrm{CI}[0.09,0.20]$

399 for every doubling of the block number. The interaction between Group and log2(block) was not

400 statistically significant, $\mathrm{F}(1,24.78)=1.23, \mathrm{p}=0.28$, providing no evidence that the learning rates

401 differed between the two groups.

402

403

404 Figure 3 | 3D-MOT task training data: Average speed thresholds for the Professional (red

405 triangles) and Amateur (black circles) groups are plotted as a function of block number.

406 Participants completed three blocks in each of five sessions. The error bars represent standard 
407 deviations of the mean. Thin lines represent logarithmic regressions, which fit individual

408 participants' data (dashed red for Professionals, solid black for Amateurs), and thick lines fit the

409 groups' data. Speed is expressed in arbitrary speed units.

410

411

412 Association between attention, working memory, and short-term memory

413 Previous studies have indicated that visual working memory (WM) and selective attention are

414 related both on a behavioral and neuroanatomical level (Awh \& Jonides, 2001; Gazzaley \&

415 Nobre, 2012). It has been argued that selective attention is crucial for effectively filtering

416 irrelevant information at the encoding phase (Vogel, McCollough, \& Machizawa, 2005).

417 Because WM has a limited capacity, attention is required to appropriately select the relevant

418 information to encode in WM to avoid unnecessary clutter (Ma, Husain, \& Bays, 2014; Myers,

419 Stokes, \& Nobre, 2017). Selective attention may also be involved in maintaining information

420 activated in WM (Awh \& Jonides, 2001; Awh, Vogel, \& Oh, 2006). Many studies also report an

421 association between WM and STM (Conway, Cowan, Bunting, Therriault, \& Minkoff, 2002;

422 Engle, Tuholski, Laughlin, \& Conway, 1999; Kail \& Hall, 2001), as STM is often theorized as a 423 subcomponent of WM (Cowan, 1998; Engle et al., 1999; Kail \& Hall, 2001).

425 Figure 4 shows the results of bivariate Spearman's correlations among attention and processing 426 speed outcome measures (d2 Test of Attention TN-E, WAIS-IV Coding, and the average speed

427 threshold for the 3D-MOT task at baseline), and among auditory and visual WM and STM 428 outcome measures (Spatial Span Forward and Backward subscales, Digit Span Forward,

429 Backward, and Sequencing subscales). We only examined correlations for both groups together, 
430 as the sample sizes in each group were not sufficient to provide stable correlation estimates

431 (Schönbrodt \& Perugini, 2013). As can be seen, d2 TN-E scores were correlated with Spatial

432 Span Backward subscale $\left(r_{s}=0.50, \mathrm{p}=0.01\right)$, and with the WAIS-IV Coding $\left(\mathrm{r}_{\mathrm{s}}=0.45, \mathrm{p}=\right.$

433 0.01), but not with Spatial Span Forward $\left(r_{s}=0.21, \mathrm{p}=0.26\right)$. Thus, our measure of selective

434 attention correlated with measures of vWM and processing speed, but not with vSTM. The d2

435 TN-E score also correlated with the Digit Span Sequencing subscale $\left(r_{s}=0.51, \mathrm{p}=0.01\right)$, but not

436 with the Forward or Backward subscales. The Spatial Span Forward and Backward subscales

437 were moderately correlated with each other $\left(r_{s}=0.43, p=0.02\right)$. Performance on the 3D-MOT

438 task showed a strong correlation with the Spatial Stan Forward $\left(r_{s}=0.68, \mathrm{p}<0.001\right)$ and

439 Backward $\left(r_{s}=0.69, \mathrm{p}<0.001\right)$ subscales, indicating that these two tasks index similar cognitive

440 capacities. Finally, the Spatial Span Forward was the only variable that correlated with the

441 average weekly hours of video game play $\left(r_{s}=0.45, \mathrm{p}=0.12\right)$. Keeping in mind that the

442 Professional and Amateur groups showed a large difference in their average weekly hours of

443 video game play, this positive association is consistent with the previously-reported difference in

444 Spatial Span performance in the two groups.

\section{Discussion}

447 To gain a better understanding of the cognitive determinants of expertise in action video games,

448 the current study compared the performance of professional action video gamers with that of

449 video gamers who play similar FPS games non-competitively on a set of eight

450 neuropsychological tests, and on their ability to improve their performance on a multiple objects

451 tracking task. The results revealed that Professionals performed better than Amateurs on some

452 measures in the Spatial Span, Digit Span, d2 Test of Attention, and 3D-MOT tasks. These results 
453 indicate that high performance in FPS video games is associated with enhanced abilities in visual

454 and auditory short-term memory, selective and sustained attention, and visual spatial attention.

455 There was no evidence for any group differences in performance on tasks that evaluated

456 executive functions, perceptual manipulation, or manual dexterity. Furthermore, both groups

457 showed similar capacity to improve their performance in the 3D-MOT task with training. Given

458 the cross-sectional, observational nature of this group comparison, this study cannot speak to the

459 causality of the differences in cognitive performance and video game expertise. The presence of

460 differences between groups may either indicate that certain cognitive abilities are conducive to

461 achieving high performance in FPS games, or that the greater amount of experience with FPS

462 games in the professional group lead to improved performance in the above-mentioned abilities.

463

464 The results from the $\mathrm{d} 2$ Test of Attention indicate that Professional players may have better

465 selective and sustained attention than Amateur players. This finding is consistent with previous

466 studies that reported attentional benefits in non video-game players following practice with

467 action video games (Belchior et al., 2013; Green \& Bavelier, 2003; Green \& Bavelier, 2006;

468 Spence et al., 2009). It is also consistent with results of a meta-analysis that found strong

469 evidence for a robust effect of action video games on attention using similar tasks (Bediou et al.,

470 2018). Some authors have raised the possibility that AVG players show higher performance in

471 attention tasks because they employ a more optimal visual search strategy (Clark, Fleck, \&

472 Mitroff, 2011). We believe that differences in search strategies were minimized in the d2 test,

473 because participants were instructed to search line by line without the possibility of going back.

474 Furthermore, although Professional players processed, on average, more stimuli than Amateurs,

475 they maintained the same accuracy rate, suggesting no apparent trade-offs between speed and 
476 accuracy. These results suggest that Professional players displayed enhanced visual selective

477 attention compared to Amateurs. Furthermore, the performance of Professional players was more

478 stable than Amateurs' in terms of items processed per line, suggesting better capacities in

479 sustained attention. Sustained attention is an important ability in the context of professional

480 videogaming, where players often need to train for many hours consecutively. While previous

481 research has demonstrated that AVG players hold an advantage over non-players on attention

482 (Castel et al., 2005; Green \& Bavelier, 2006), the current results indicate that selective and

483 sustained attention are further enhanced in elite video game experts. Thus, taken together, these

484 results suggest that attention capacities could be influenced by AVGs.

485

486 Previous studies that used change detection tasks with simple and complex stimuli have reported

487 better vSTM capacities in action video game players (Blacker \& Curby, 2013; Wilms, Petersen,

488 \& Vangkilde, 2013). In the present study, vSTM was indexed using the Spatial Span Forward

489 subscale, which showed the greatest benefit in performance in the Professional group. Previous

490 researchers have proposed that improvements in vSTM could be linked to the enhancement of

491 visual selective attention that enables to select task-relevant and ignore task-irrelevant

492 information (Bavelier, Green, Pouget, \& Schrater, 2012). In the context of our study, the

493 bivariate correlation did not show a statistically significant association between our attention and

494 vSTM measures, suggesting that the benefits in vSTM seen here are not strongly related to

495 selective attention abilities.

496

497 While previous studies mainly examined the effects of video games on visual cognition, a few

498 studies have also noted benefits of video games on performance in auditory or multisensory 
499 tasks. For example, adult video game players showed better temporal processing of multisensory

500 stimuli than non-players (Donohue, Woldorff, \& Mitroff, 2010) and training with action video

501 games was associated with improvements in reading and phonological short-term memory in

502 children with dyslexia (Franceschini \& Bertoni, 2019; Franceschini et al., 2013). In the present

503 study, there was some evidence for a benefit in auditory memory in the Digit Span test for the

504 Professional group, although there was no evidence of a difference in the Forward subscale that

505 indexes auditory short-term memory. While experience with video games may impact auditory

506 and multisensory performance, we do not find evidence that auditory short-term memory is a

507 characteristic of video game expertise.

508

509 The present study suggests a link between the level of video gaming expertise and the ability to

510 perform an abstract dynamic task. The 3D-MOT task strongly engages several attention and

511 mental skills; performing this task well requires selective, dynamic, distributed, and sustained

512 attention skills (Faubert, 2013). Professional video game players performed better than Amateurs

513 on the 3D-MOT task across the 5 training sessions, suggesting that video game expertise is also

514 related to perceptive-cognitive ability. This is consistent with the idea that Professionals players

515 must be efficient at extracting meaningful information from a visual scene in order to anticipate

516 and make good decisions. The 3D-MOT task results are consistent with the enhancement of

517 motion perception highlighted by other studies that employed the multiple objects tracking or

518 dots motion tasks (Boot, Kramer, Simons, Fabiani, \& Gratton, 2008; Green \& Bavelier, 2006;

519 Hutchinson \& Stocks, 2013). These results are also consistent with the growing evidence that

520 action video game experience has an impact on the dorsal pathway (Chopin, Bediou, \& Bavelier,

521 2019). The dorsal pathway is a network involved in spatial working memory. It specializes in 
522 capturing dynamic spatial and temporal relationships between multiple items (Kravitz, Saleem,

523 Baker, Ungerleider, \& Mishkin, 2013), and is engaged during multiple object tracking tasks

524 (Blumberg, Peterson, \& Parasuraman, 2015; Howe, Horowitz, Morocz, Wolfe, \& Livingstone,

525 2009). The dorsal pathway is often referred to as the 'where/how' pathway, as it is involved in

526 localizing and guiding motor action (Chopin et al., 2019). Furthermore, the professional and

527 casual video game players in the current study showed similar learning rates across the five

528 sessions, in contrast to other studies, where professional sports athletes showed enhanced

529 abilities to improve their 3D-MOT performance with training relative to amateur athletes

530 (Faubert, 2013).

531

532 While the effect in the multiple object tracking task is consistent with differences in the dorsal 533 pathway, there were no group differences in the Grooved Pegboard task, which relies on action

534 planning and visuomotor coordination that also depends on the dorsal pathway. Previous studies 535 found that players have better hand-eye coordination than non-players, but this benefit was not 536 associated with the amount of time spent engaging in the games (Griffith, Voloschin, Gibb, \&

537 Bailey, 1983). Action video games were also shown to improve visuomotor control in an 538 intervention study ( $\mathrm{Li}, \mathrm{Chen}, \&$ Chen, 2016). Together with the current findings, this suggests

539 that the benefits of action video games on motor dexterity and visuomotor coordination are

540 limited, in that extended practice does not lead to larger benefits.

542 The current results also do not provide evidence for any differences in working memory

543 associated with professional gaming, as the average performance on the Backward subscales of

544 the Spatial Span and Digit Span tasks did not differ between groups. As mentioned earlier, 
545 previous studies have emphasized that WM, which involves maintaining elements active and

546 quickly accessible, is intricately linked with the concept of selective attention, both on a

547 behavioral and anatomical level (Awh \& Jonides, 2001; Engle, 2002; Hitch, Hu, Allen, \&

548 Baddeley, 2018). Supporting this overlap between the two constructs, we observed positive

549 associations between outcome measures of vWM, selective attention, and vSTM. Nevertheless,

550 while there was some evidence for enhanced selective attention in professional players,

551 performance in tasks relying on auditory or visual working memory were similar in both groups.

552

553 The present results also do not provide evidence for any differences in executive functions

554 between Professional players and Amateurs, as measured by the inhibition and flexibility

555 subscales of the Stroop task. Mental flexibility has been cited as one of the strongest

556 enhancements in real-time strategy games (Basak, Boot, Voss, \& Kramer, 2008). The meta-

557 analysis in AVGs conducted by Bediou (2017) suggested a medium size effect for flexibility,

558 and only a weak effect for inhibition. Given that the current study is only well suited to detect

559 large effects, our findings are consistent with previous results. There is also no evidence of any

560 group differences in visual planning skills or visual reasoning. These results are consistent with

561 the results of Boot and colleagues (2008), who found no association between video game

562 practice and planning skills, using the Tower of London task (Tunstall, 1999).

563

564 Previous studies have found that video game players are faster than non-video game players in

565 reaction time tasks (Castel et al., 2005; Dye et al., 2009). However, the current study found no

566 reliable difference in performance in the main visual processing speed task (WAIS-IV Coding),

567 nor in the Grooved Peg task, which relies on rapid manual dexterity and hand-eye coordination. 
568 That said, the TN measure of the $\mathrm{d} 2$ Test of Attention showed that Professional players process a

569 greater number of stimuli in a given time than Amateurs, suggesting that video game expertise is

570 related to a better ability to process simple visual information. The different results provided by

571 the $\mathrm{d} 2$ and Coding tests address a question raised by Dye, Green and Bavelier (2009), who

572 wondered whether the advantages of video gaming are restricted to tasks involving only binary

573 responses, or if they can generalize to more complex tasks with multiple response alternatives.

574 The Coding task requires participants to quickly code a series of items using the correct symbol

575 among a total of nine codes. Thus, in addition to speed of processing, good performance in the

576 Coding task requires attention, motor speed, visuo-perceptual abilities, and dexterity to write the

577 appropriate symbols (Jaeger, 2018). In contrast, the participant response in the $\mathrm{d} 2$ test involves a

578 choice between one of two options: to mark or not to mark the symbol. The two-choice response

579 in the $\mathrm{d} 2$ test is closer to that used in the literature demonstrating the benefits of video gaming on

580 processing speed (Dye et al., 2009). The current findings may suggest that video game expertise

581 is related to a better ability to process simple visual information, rather than providing a global

582 benefit in processing speed in more complex tasks.

583

584 By better understanding Professional videogaming, we can provide clues as to how this expertise

585 and the corresponding performance best develops, and therefore learn how to support it

586 (Farrington-Darby \& Wilson, 2006). In order to effectively study video game expertise, it is

587 crucial to define it appropriately. The definitions of video gamers in previous studies ignored

588 potential differences between video game players who had played 5 hours per week over the

589 previous 6 months, and those who had played more than 20 hours per week over the previous 10

590 years. Moreover, the assumption that recent video gaming experience reflects expertise could be 
591 mistaken (Latham et al., 2013). Failure to consider expertise in terms of performance may also

592 contribute to some of the mixed results in the literature. By applying the same performance

593 criteria to video gaming research, differences between professional and amateur players allowed

594 us to determine the factors that potentially underlie high-level performance, such as attention,

595 STM, and perceptive-cognitive ability.

596

597 The current study has serval limitations. First, due to our limited sample size, the current study

598 had low power to detect small or medium effects (with alpha $=0.05$, power $=0.80$ ). Thus, we

599 should remain careful in our interpretation of null results, as differences might exist but failed to

600 be detected. Furthermore, the gender of the study participants may have acted as a confounding

601 variable since our Professional players group was composed only of men, whereas our Amateur

602 group had four women, although women's results did not differ from men's within the same

603 group. Finally, the experimenter who administered the measures was not blind to the participant

604 group, which may have introduced some bias.

605

606 Conclusions

607 In summary, this study was the first to examine the cognitive basis of elite performance in action

608 video game players. Our results revealed that elite players show the greatest performance

609 advantage in tests of visual spatial short-term memory and of visual attention. Furthermore,

610 professional action video gamers showed a better ability to track multiple objects within a

611 complex and dynamic scene than amateur players, but both groups showed similar rates of

612 improvement in the task with training. Further research is needed to clarify whether the observed

613 differences in cognitive abilities emerge as a result of intense practice in action video games, or 
614 whether certain cognitive profiles are beneficial for achieving high-level performance in video 615 gaming.

616

\section{Conflict of interest}

618 Jocelyn Faubert is the director of the Faubert Lab at the University of Montreal and the Chief

619 Science Officer of Cognisens Athletics Inc., the producer of the commercial version of the 3D-

620 MOT task that was used in this study. In this capacity, he holds shares in the company. Taylor

621 Johnson and Trevor Love are employed by Infinite Esports and Entertainments, the parent

622 company of Houston Outlaws. This does not alter our adherence to the journal policies on

623 sharing data and materials.

624

625 Acknowledgments

626 We would like to acknowledge Russel Smith, Matt Men, and Stephen Suttle for their support

627 during data collection.

628 
630

631

632

633

634

635

636

637

638

639

640

641

642

643

644

645

646

647

648

649

650

651

652

653

654

655

656

657

658

659

660

661

662

663

664

665

666

667

668

669

Andrews, G., \& Murphy, K. (2006). Does video game playing improve executive functioning?

Awh, E., \& Jonides, J. (2001). Overlapping mechanisms of attention and spatial working memory. Trends in cognitive sciences, 5(3), 119-126.

Awh, E., Vogel, E. K., \& Oh, S.-H. (2006). Interactions between attention and working memory. Neuroscience, 139(1), 201-208.

Baayen, R. H., Davidson, D. J., \& Bates, D. M. (2008). Mixed-effects modeling with crossed random effects for subjects and items. Journal of memory and language, 59(4), 390-412.

Basak, C., Boot, W. R., Voss, M. W., \& Kramer, A. F. (2008). Can training in a real-time strategy video game attenuate cognitive decline in older adults? Psychol Aging, 23(4), 765-777. doi:10.1037/a0013494

Bates, D., Maechler, M., Bolker, B., Walker, S., Christensen, R. H. B., Singmann, H., . . Bolker, M. B. (2015). Package 'Ime4'. Convergence, 12(1), 2.

Bavelier, D., Green, C. S., Pouget, A., \& Schrater, P. (2012). Brain plasticity through the life span: learning to learn and action video games. Annual review of neuroscience, 35, 391-416.

Bediou, B., Adams, D. M., Mayer, R. E., Tipton, E., Green, C. S., \& Bavelier, D. (2018). Meta-analysis of action video game impact on perceptual, attentional, and cognitive skills. Psychol Bull, 144(1), 77-110. doi:10.1037/bul0000130

Belchior, P., Marsiske, M., Sisco, S. M., Yam, A., Bavelier, D., Ball, K., \& Mann, W. C. (2013). Video game training to improve selective visual attention in older adults. Computers in Human Behavior, 29(4), 1318-1324.

Blacker, K. J., \& Curby, K. M. (2013). Enhanced visual short-term memory in action video game players. Attention, Perception, \& Psychophysics, 75(6), 1128-1136.

Blumberg, E. J., Peterson, M. S., \& Parasuraman, R. (2015). Enhancing multiple object tracking performance with noninvasive brain stimulation: a causal role for the anterior intraparietal sulcus. Frontiers in systems neuroscience, 9, 3.

Boot, W. R., Kramer, A. F., Simons, D. J., Fabiani, M., \& Gratton, G. (2008). The effects of video game playing on attention, memory, and executive control. Acta psychologica, 129(3), 387-398.

Brickenkam, R., \& Zillmer, E. (1998). d2-Test of Attention (1st US edition ed.).(D. Emmans, Trans.) Cambridge/Toronto: Oxford/Bern/Göttingen: Hogrefe.

Brown, M. T., \& Wicker, L. R. (2000). Discriminant analysis Handbook of applied multivariate statistics and mathematical modeling (pp. 209-235): Elsevier.

Cain, M. S., Landau, A. N., \& Shimamura, A. P. (2012). Action video game experience reduces the cost of switching tasks. Attention, Perception, \& Psychophysics, 74(4), 641-647.

Castel, A. D., Pratt, J., \& Drummond, E. (2005). The effects of action video game experience on the time course of inhibition of return and the efficiency of visual search. Acta Psychol (Amst), 119(2), 217-230. doi:10.1016/j.actpsy.2005.02.004

Chi, M. T., Glaser, R., \& Farr, M. J. (2014). The nature of expertise: Psychology Press.

Chopin, A., Bediou, B., \& Bavelier, D. (2019). Altering perception: the case of action video gaming. Current opinion in psychology. 
670 Clark, K., Fleck, M. S., \& Mitroff, S. R. (2011). Enhanced change detection performance reveals

671

672

673

674

675

676

677

678

679

680

681

682

683

684

685

686

687

688

689

690

691

692

693

694

695

696

697

698

699

700

701

702

703

704

705

706

707

708 improved strategy use in avid action video game players. Acta psychologica, 136(1), 6772.

Colzato, L. S., van den Wildenberg, W. P., Zmigrod, S., \& Hommel, B. (2013). Action video gaming and cognitive control: playing first person shooter games is associated with improvement in working memory but not action inhibition. Psychological Research, 77(2), 234-239.

Colzato, L. S., Van Leeuwen, P. J., Van Den Wildenberg, W., \& Hommel, B. (2010). DOOM'd to switch: superior cognitive flexibility in players of first person shooter games. Frontiers in psychology, 1, 8.

Conway, A. R., Cowan, N., Bunting, M. F., Therriault, D. J., \& Minkoff, S. R. (2002). A latent variable analysis of working memory capacity, short-term memory capacity, processing speed, and general fluid intelligence. Intelligence, 30(2), 163-183.

Cowan, N. (1998). Attention and memory: An integrated framework (Vol. 26): Oxford University Press.

Delis, D. C., Kaplan, E., Kramer, J. H., Delis, D., \& Kramer, J. (2001). Delis-Kaplan executive function system (D-KEFS). Examiner's manual.

Dobrowolski, P., Hanusz, K., Sobczyk, B., Skorko, M., \& Wiatrow, A. (2015). Cognitive enhancement in video game players: The role of video game genre. Computers in Human Behavior, 44, 59-63.

Donohue, S. E., Woldorff, M. G., \& Mitroff, S. R. (2010). Video game players show more precise multisensory temporal processing abilities. Attention, Perception, \& Psychophysics, 72(4), 1120-1129. doi:10.3758/APP.72.4.1120

Dye, M. W., Green, C. S., \& Bavelier, D. (2009). The development of attention skills in action video $\begin{array}{llll}\text { game } & \text { players. } & \text { 1780-1789. }\end{array}$ doi:10.1016/j.neuropsychologia.2009.02.002

Dye, M. W., Green, C. S., \& Bavelier, D. (2009). Increasing speed of processing with action video games. Current directions in psychological science, 18(6), 321-326.

Engle, R. W. (2002). Working memory capacity as executive attention. Current directions in psychological science, 11(1), 19-23.

Engle, R. W., Tuholski, S. W., Laughlin, J. E., \& Conway, A. R. (1999). Working memory, short-term memory, and general fluid intelligence: a latent-variable approach. Journal of Experimental Psychology: General, 128(3), 309.

Ericsson, K. A., \& Towne, T. J. (2013). Experts and their superior performance The Oxford handbook of cognitive psychology.

Farrington-Darby, T., \& Wilson, J. R. (2006). The nature of expertise: A review. Applied ergonomics, 37(1), 17-32.

Faubert, J. (2013). Professional athletes have extraordinary skills for rapidly learning complex and neutral dynamic visual scenes. Scientific reports, 3, 1154.

Faubert, J., \& Sidebottom, L. (2012). Perceptual-cognitive training of athletes. Journal of Clinical Sport Psychology, 6(1), 85-102. 
709

710

711

712

713

714

715

716

717

718

719

720

721

722

723

724

725

726

727

728

729

730

731

732

733

734

735

736

737

738

739

740

741

742

743

744

745

746

747

748

749

750

751

752

Feng, J., Spence, I., \& Pratt, J. (2007). Playing an action video game reduces gender differences in spatial cognition. Psychological science, 18(10), 850-855.

Franceschini, S., \& Bertoni, S. (2019). Improving action video games abilities increases the phonological decoding speed and phonological short-term memory in children with developmental dyslexia. Neuropsychologia, 130, 100-106.

Franceschini, S., Gori, S., Ruffino, M., Viola, S., Molteni, M., \& Facoetti, A. (2013). Action video games make dyslexic children read better. Current Biology, 23(6), 462-466.

Gazzaley, A., \& Nobre, A. C. (2012). Top-down modulation: bridging selective attention and working memory. Trends in Cognitive Sciences, 16(2), 129-135.

Glass, B. D., Maddox, W. T., \& Love, B. C. (2013). Real-time strategy game training: emergence of a cognitive flexibility trait. PLoS One, 8(8), e70350. doi:10.1371/journal.pone.0070350

Green, C. S., \& Bavelier, D. (2003). Action video game modifies visual selective attention. Nature, 423(6939), 534-537. doi:10.1038/nature01647

Green, C. S., \& Bavelier, D. (2006). Effect of action video games on the spatial distribution of visuospatial attention. J Exp Psychol Hum Percept Perform, 32(6), 1465-1478. doi:10.1037/0096-1523.32.6.1465

Green, C. S., \& Bavelier, D. (2006). Enumeration versus multiple object tracking: The case of action video game players. Cognition, 101(1), 217-245.

Griffith, J. L., Voloschin, P., Gibb, G. D., \& Bailey, J. R. (1983). Differences in eye-hand motor coordination of video-game users and non-users. Perceptual and motor skills, 57(1), 155158.

Halekoh, U., \& Højsgaard, S. (2014). A kenward-roger approximation and parametric bootstrap methods for tests in linear mixed models-the R package pbkrtest. Journal of Statistical Software, 59(9), 1-30.

Hitch, G. J., Hu, Y., Allen, R. J., \& Baddeley, A. D. (2018). Competition for the focus of attention in visual working memory: perceptual recency versus executive control. Annals of the New York Academy of Sciences.

Howe, P. D., Horowitz, T. S., Morocz, I. A., Wolfe, J., \& Livingstone, M. S. (2009). Using fMRI to distinguish components of the multiple object tracking task. Journal of vision, 9(4), 10-10.

Hutchinson, C. V., \& Stocks, R. (2013). Selectively enhanced motion perception in core video gamers. Perception, 42(6), 675-677.

Irons, J. L., Remington, R. W., \& McLean, J. P. (2011). Not so fast: Rethinking the effects of action video games on attentional capacity. Australian Journal of Psychology, 63(4), 224-231.

Jaeger, J. (2018). Digit symbol substitution test: the case for sensitivity over specificity in neuropsychological testing. Journal of clinical psychopharmacology, 38(5), 513.

Kail, R., \& Hall, L. K. (2001). Distinguishing short-term memory from working memory. Memory \& Cognition, 29(1), 1-9.

Karle, J. W., Watter, S., \& Shedden, J. M. (2010). Task switching in video game players: Benefits of selective attention but not resistance to proactive interference. Acta psychologica, 134(1), 70-78.

Kessels, R. P., van den Berg, E., Ruis, C., \& Brands, A. M. (2008). The backward span of the Corsi Block-Tapping Task and its association with the WAIS-III Digit Span. Assessment, 15(4), 426-434.

Peer) reviewing PDF | (2020:01:44849:2:1:NEW 18 Sep 2020) 
753

754

755

756

757

758

759

760

761

762

763

764

765

766

767

768

769

770

771

772

773

774

775

776

777

778

779

780

781

782

783

784

785

786

787

788

789

790

791

792

793

794

795

Kravitz, D. J., Saleem, K. S., Baker, C. I., Ungerleider, L. G., \& Mishkin, M. (2013). The ventral visual pathway: an expanded neural framework for the processing of object quality. Trends in cognitive sciences, 17(1), 26-49.

Kuznetsova, T., Brockhoff, P. B., \& Christensen, R. (2014). ImerTest: tests for random and fixed effects for linear mixed effect models (Imer objects of Ime4 package).. 2.0-6.

Latham, A. J., Patston, L. L., \& Tippett, L. J. (2013). Just how expert are "expert" video-game players? Assessing the experience and expertise of video-game players across "action" video-game genres. Frontiers in Psychology, 4, 941. doi:10.3389/fpsyg.2013.00941

Legault, I., Allard, R., \& Faubert, J. (2013). Healthy older observers show equivalent perceptualcognitive training benefits to young adults for multiple object tracking. Frontiers in psychology, 4, 323.

Levitt, H. (1971). Transformed up-down methods in psychoacoustics. The Journal of the Acoustical society of America, 49(2B), 467-477.

Li, L., Chen, R., \& Chen, J. (2016). Playing action video games improves visuomotor control. Psychological science, 27(8), 1092-1108.

Luke, S. G. (2017). Evaluating significance in linear mixed-effects models in R. Behavior research methods, 49(4), 1494-1502.

Ma, W. J., Husain, M., \& Bays, P. M. (2014). Changing concepts of working memory. Nature Neuroscience, 17(3), 347.

Mann, D. T., Williams, A. M., Ward, P., \& Janelle, C. M. (2007). Perceptual-cognitive expertise in sport: A meta-analysis. Journal of Sport and Exercise Psychology, 29(4), 457-478.

Murphy, K., \& Spencer, A. (2009). Playing video games does not make for better visual attention skills. Journal of Articles in Support of the Null Hypothesis, 6(1).

Myers, N. E., Stokes, M. G., \& Nobre, A. C. (2017). Prioritizing information during working memory: beyond sustained internal attention. Trends in Cognitive Sciences, 21(6), 449461.

NACE. (2020). Collegiate Esports Governing Body. Retrieved from https://nacesports.org/wpcontent/uploads/2019/02/December-2018-NACE-Flyer.pdf

Newzoo. (2020). Global Esport Market Report. Retrieved from https://newzoo.com/products/reports/global-esports-market-report/

Parsons, B., Magill, T., Boucher, A., Zhang, M., Zogbo, K., Bérubé, S., Scheffer, O., Beauregard, M., \& Faubert, J. (2016). Enhancing Cognitive Function Using PerceptualCognitive Training. Clinical EEG and Neuroscience, 47(1), 37-47. https://doi.org/10.1177/1550059414563746

Powers, K. L., \& Brooks, P. J. (2014). Evaluating the specificity of effects of video game training. Learning by playing: Video gaming in education, 302-329.

Pylyshyn, Z. W., \& Storm, R. W. (1988). Tracking multiple independent targets: Evidence for a parallel tracking mechanism. Spatial vision, 3(3), 179-197.

Romeas, T., Guldner, A., \& Faubert, J. (2016). 3D-Multiple Object Tracking training task improves passing decision-making accuracy in soccer players. Psychology of Sport and Exercise, 22, 1-9.

Scharfen, H. E., \& Memmert, D. (2019). Measurement of cognitive functions in experts and elite athletes: A meta-analytic review. Applied Cognitive Psychology, 33(5), 843-860.

Peer) reviewing PDF | (2020:01:44849:2:1:NEW 18 Sep 2020) 
796

797

798

799

800

801

802

803

804

805

806

807

808

809

810

811

812

813

814

815

816

817

818

819

820

821

822

823

824

825

826

827

828

829

830

831

832

833

834

835

836

837

838

839

Schönbrodt, F. D., \& Perugini, M. (2013). At what sample size do correlations stabilize? Journal of Research in Personality, 47(5), 609-612.

Smith, K. N., Lamb, K. N., \& Henson, R. K. (2020). Making Meaning out of MANOVA: The Need for Multivariate Post Hoc Testing in Gifted Education Research. Gifted Child Quarterly, 64(1), 41-55.

Spence, I., Yu, J. J., Feng, J., \& Marshman, J. (2009). Women match men when learning a spatial skill. Journal of Experimental Psychology: Learning, Memory, and Cognition, 35(4), 1097.

SpillGames. (2013). State of online gaming report. http://auth-83051f68-ec6c-44e0-afe5 bd8902acff57.cdn.spilcloud.com/v1/archives/1384952861.25_State_of_Gaming_2013_ US_FINAL.pdf

Statista. (2017). Value of the video game market in the United States from 2011 to 2020 (in million U.S. dollars). Retrieved from https://www.statista.com/statistics/246892/valueof-the-video-game-market-in-the-us/

Statista. (2019). Most popular video games among gamers in the United States in 2019 Retrieved from https://www.statista.com/statistics/1079072/most-popular-video-games/

Statista. (2020). Number of active video gamers worldwide from 2014 to 2021. Retrieved from https://www.statista.com/statistics/748044/number-video-gamers-world/

Strauss, E., Sherman, E. M., \& Spreen, O. (2006). A compendium of neuropsychological tests: Administration, norms, and commentary: American Chemical Society.

Swann, C., Moran, A., \& Piggott, D. (2015). Defining elite athletes: Issues in the study of expert performance in sport psychology. Psychology of Sport and Exercise, 16, 3-14.

Team, R. C. (2018). R Foundation for Statistical Computing; Vienna, Austria: 2015. R: A language and environment for statistical computing, 2013.

Torchiano, M. (2016). effsize: efficient effect size computation (R package): Vienna, Austria: R Foundation for Statistical Computing. Retrieved from ....

Tullo, D., Faubert, J., \& Bertone, A. (2018). The characterization of attention resource capacity and its relationship with fluid reasoning intelligence: A multiple object tracking study. Intelligence, 69, 158-168.

Tunstall, J. R. (1999). Improving the utility of the Tower of London: A neuropsychological test of planning: Griffith University Brisbane,, Australia.

Vaughan, R. S., \& Laborde, S. (2020). Attention, working-memory control, working-memory capacity, and sport performance: The moderating role of athletic expertise. European Journal of Sport Science(just-accepted), 1-27.

Vogel, E. K., McCollough, A. W., \& Machizawa, M. G. (2005). Neural measures reveal individual differences in controlling access to working memory. Nature, 438(7067), 500-503.

Voss, M. W., Kramer, A. F., Basak, C., Prakash, R. S., \& Roberts, B. (2010). Are expert athletes 'expert'in the cognitive laboratory? A meta-analytic review of cognition and sport expertise. Applied Cognitive Psychology, 24(6), 812-826.

Wang, Y.-P., \& Gorenstein, C. (2013). Psychometric properties of the Beck Depression InventoryII: a comprehensive review. Brazilian Journal of Psychiatry, 35(4), 416-431.

Wechsler, D. (2011). WAIS-IV: échelle d'intelligence de Wechsler pour adultes: Éditions du Centre de psychologie appliquée.

Weiss, L. G., Saklofske, D. H., Coalson, D., \& Raiford, S. E. (2010). WAIS-IV clinical use and interpretation: Scientist-practitioner perspectives: Academic Press.

Peer) reviewing PDF | (2020:01:44849:2:1:NEW 18 Sep 2020) 
840 Wilms, I. L., Petersen, A., \& Vangkilde, S. (2013). Intensive video gaming improves encoding speed 841 to visual short-term memory in young male adults. Acta psychologica, 142(1), 108-118. 842 


\section{Figure 1}

Five stages of a trial in the 3D-MOT task

a) Presentation phase, in which eight spheres appear in random locations in a 3D space. b) Indexing phase, in which four spheres are cued as targets with a 1 second colour change to red and the appearance of a halo. c) Movement phase, in which all spheres move for eight seconds in random directions, crisscrossing and bouncing off of each other and the walls of the 3D space and the participant is asked to keep track of the targets, while fixating at the central fixation point. d) Identification phase, in which the immobilized spheres are numbered 1 - 8 and the participant is asked to identify the four targets. e) Feedback phase, in which the target spheres are highlighted in red and a star is shown if all four targets were selected correctly.

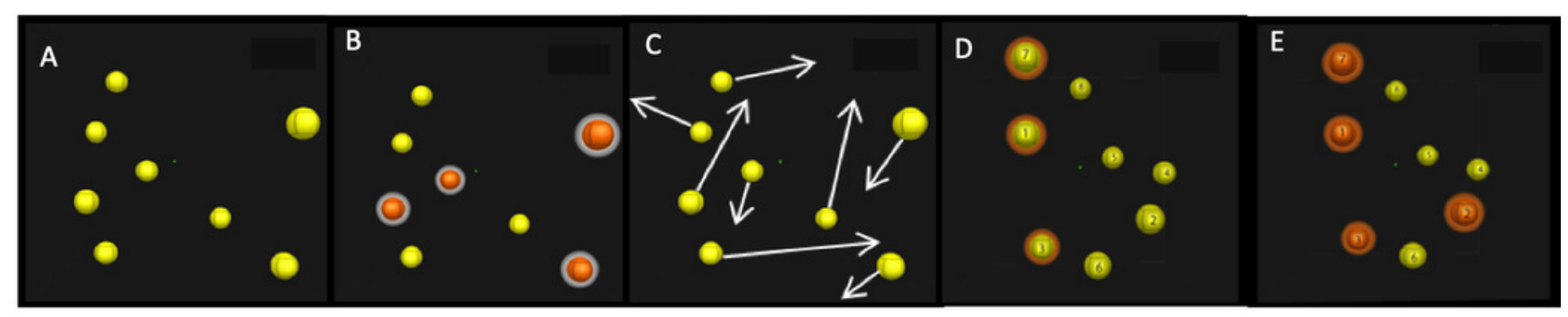


Figure 2

\section{Results of neuropsychological tests}

Large symbols show the mean group score and small symbols show individual participant data for the Amateur (black circles) and Professional (red triangles) groups. Error bars represent 1 SD of the mean. The dashed lines represent the maximum score possible for each variable.

A.

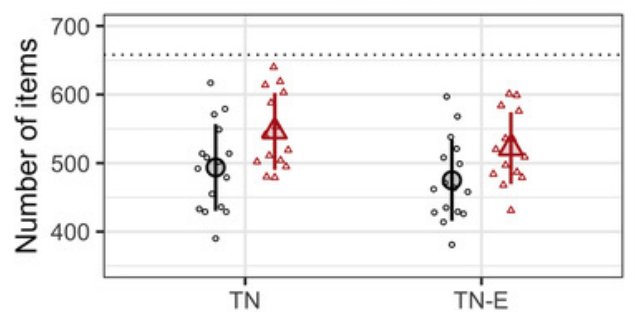

c.

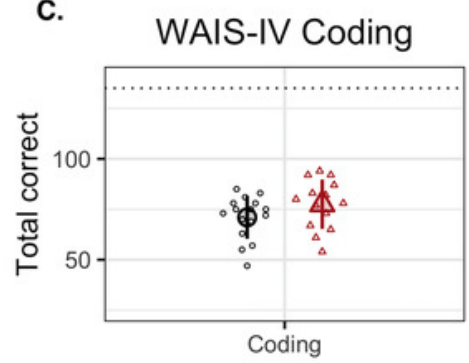

F. D-KEFS Towers
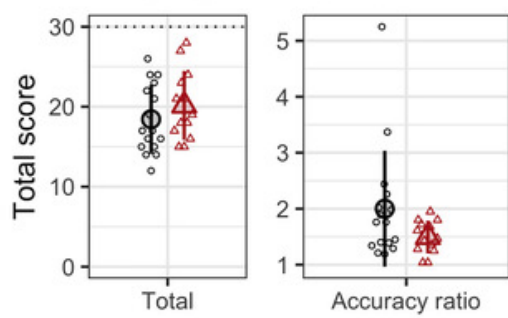

D.

D. WAIS-IV Visual Puzzles

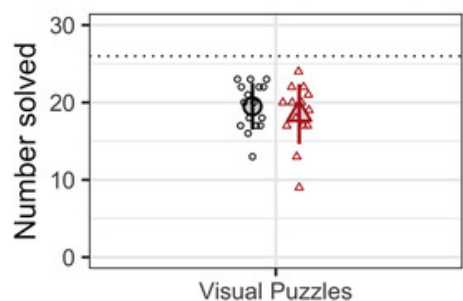

G. Grooved Pegboard

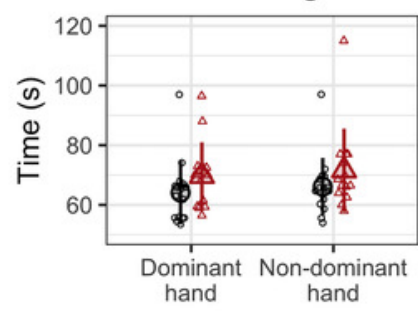

B.
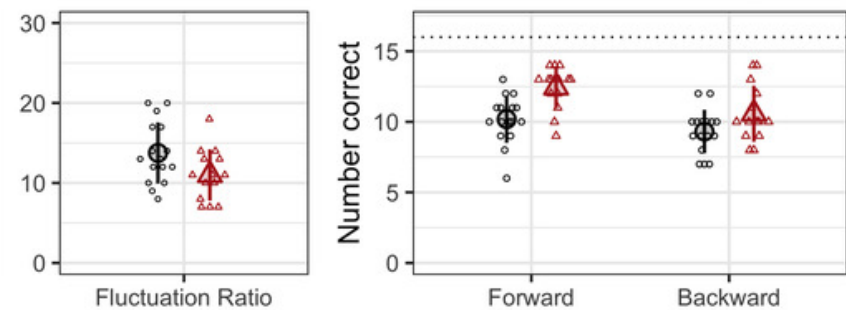

WAIS-IV Digit Span
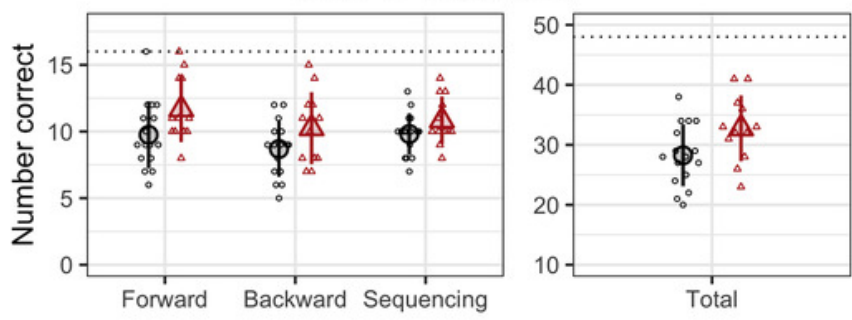

H. D-KEFS Color-Word Interference
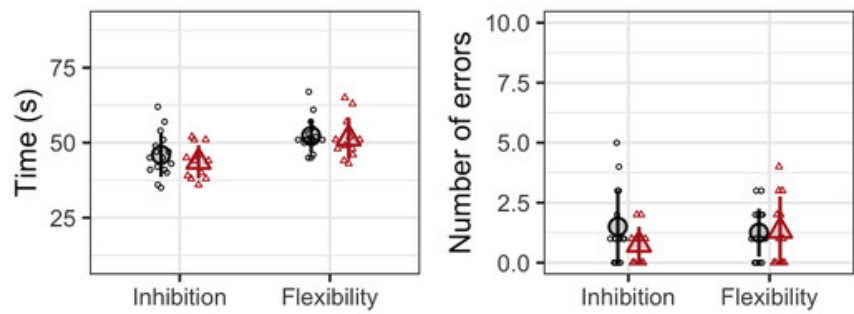

Group $\Phi$ Amateur 4 Professional 


\section{Table $\mathbf{1}$ (on next page)}

Demographic and video game experience information for the two groups

BDI-II: Beck depression inventory (II) score, FPS: first person shooter 
1 Table 1 - Demographic and video game experience information for the two groups

\begin{tabular}{|l|l|l|l|}
\hline & Professionals $(\mathrm{n}=14)$ & Amateurs $(\mathrm{n}=16)$ & Group comparison \\
\hline & $\mathrm{M}(\mathrm{SD})$ & $\mathrm{M}(\mathrm{SD})$ & \\
\hline Age (years) & $23.66(2.44)$ & $25.31(3.77)$ & $\mathrm{t}(25.9)=-1.44, \mathrm{p}=0.16$ \\
\hline Gender ratio (male : female) & $14: 0$ & $12: 4$ & $\mathrm{~N} / \mathrm{A}$ \\
\hline BDI-II score & $6.85(5.27)$ & $4.93(4.62)$ & $\mathrm{t}(24.1)=1.01, \mathrm{p}=0.32$ \\
\hline $\begin{array}{l}\text { Age started playing video } \\
\text { games (years) }\end{array}$ & $6.93(2.81)$ & $6.75(2.62)$ & $\mathrm{t}(26.8)=0.18, \mathrm{p}=0.86$ \\
\hline $\begin{array}{l}\text { Average FPS gaming per } \\
\text { week in past six months (h) }\end{array}$ & $55.79(16.72)$ & O.47 (3.48) & $\mathrm{t}(14)=10.18, \mathrm{p}=0.00$ \\
\hline $\begin{array}{l}\text { Most frequent game } \\
\text { Overwatch (14) }\end{array}$ & $\begin{array}{l}\text { Counter Strike (7), } \\
\text { Call of Duty (3), } \\
\text { Overwatch (3), } \\
\text { Rainbow 6 (1), Player } \\
\text { Unknown's } \\
\text { Battlegrounds (1), } \\
\text { Battlefield 4 (1), }\end{array}$ & $\mathrm{N} / \mathrm{A}$ \\
\hline
\end{tabular}

2 BDI-II: Beck depression inventory (II) score, FPS: first person shooter

3

4

5 


\section{Figure 3}

3D-MOT task training data.

Average speed thresholds for the Professional (red triangles) and Amateur (black circles) group are plotted as a function of block number. Participants completed three blocks in each of five sessions. The error bars represent standard deviations of the mean. Thin lines show logarithmic regression fits to individual participants' data (dashed red for Professionals, solid black for Amateurs), with thick lines showing the group fits. Speed is expressed in arbitrary speed units. 


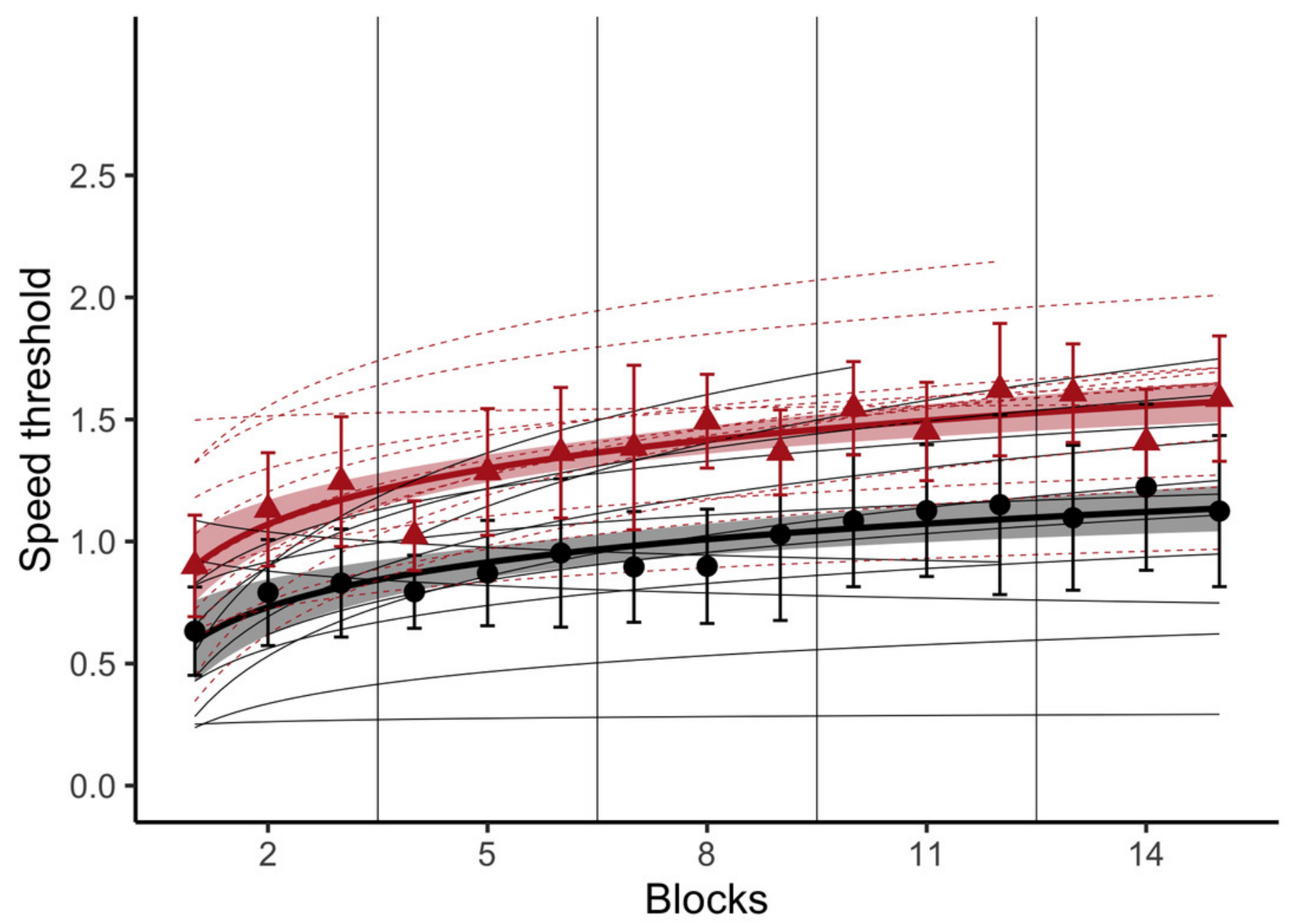

Group $\multimap$ Amateur $\_$Professional 


\section{Table 2 (on next page)}

Average raw scores for all neuropsychological tests, difference scores, and univariate inferential statistics.

Means and standard deviations (SD) of the raw scores of neuropsychological tests for Professional and Amateur video gamer participants. a, b.: $\mathrm{n}=12,13$ in the Professional group. WAIS = Weschler Adult Intelligence Scale (IV), WMS = Weschler Memory Scale (III), TN $=$ total number of items processed, TN-E $=$ total number of items processed minus the errors, $\mathrm{E} \%=$ percentage of errors, $\mathrm{CP}=$ concentration performance, $\mathrm{FR}=$ fluctuation rate (difference between the line with the minimum and maximum number of items processed). $\mathrm{DH}=$ Dominant hand, $\mathrm{NDH}=$ Non-dominant hand. Bolded $\mathrm{p}$-values are $<$ an alpha level of 0.05 (uncorrected). 
Table 3 -1Average raw scores for all neuropsychological tests, difference scores, and univariate inferential statistics.2

\begin{tabular}{|c|c|c|c|c|c|c|}
\hline Measure & $\begin{array}{l}\text { Professionals } \\
(n=14) \\
M(S D) \\
\end{array}$ & $\begin{array}{l}\text { Amateurs } \\
(\mathrm{n}=16) \\
M(\mathrm{SD}) \\
\end{array}$ & $\begin{array}{l}\text { Difference } \\
\Delta[95 \% \mathrm{CI}]\end{array}$ & $\begin{array}{l}\text { Welch t-test } \\
\text { t(df) }\end{array}$ & $p$ & $\begin{array}{l}\text { Effect size } \\
\text { Hedges' } g \\
g[95 \% \mathrm{CI}]\end{array}$ \\
\hline $\begin{array}{l}\text { D2 Test of } \\
\text { Attention } \\
-\mathrm{TN} \\
-\mathrm{E} \% \\
-\mathrm{TN}-\mathrm{E} \\
-\mathrm{CP} \\
-\mathrm{FR} \\
\end{array}$ & $\begin{array}{l}546.29(56.14) \\
4.41(2.98) \\
521.86(52.48) \\
208.79(31.62) \\
11(3.21)\end{array}$ & $\begin{array}{l}493.56(63.49) \\
3.66(2.91) \\
474.94(59.31) \\
194.38(28.41) \\
13.75(3.84) \\
\end{array}$ & $\begin{array}{l}52.73[7.98,97.47] \\
0.75[-1.46,2.96] \\
46.92[5.11,88.73] \\
14.41[-8.26,37.08] \\
-2.75[-5.39,-0.11]\end{array}$ & $\begin{array}{l}\mathrm{t}(28)=2.41 \\
\mathrm{t}(27.3)=0.7 \\
\mathrm{t}(28)=2.3 \\
\mathrm{t}(26.4)=1.31 \\
\mathrm{t}(28)=-2.14\end{array}$ & $\begin{array}{l}\mathbf{0 . 0 2} \\
0.49 \\
\mathbf{0 . 0 3} \\
0.20 \\
\mathbf{0 . 0 4}\end{array}$ & $\begin{array}{l}0.85[0.09,1.61] \\
0.25[-0.48,0.98] \\
0.81[0.05,1.57] \\
0.47[-0.27,1.21] \\
-0.75[-1.51,0]\end{array}$ \\
\hline $\begin{array}{l}\text { WAIS-IV } \\
\text { Coding }\end{array}$ & $77.5(12.25)$ & $71.0(10.61)$ & $6.5[-2.16,15.16]$ & $t(26)=1.54$ & 0.14 & $0.55[-0.19,1.3]$ \\
\hline $\begin{array}{l}\text { WMS-III } \\
\text { Spatial Span } \\
\text { - Total } \\
\text { - Forward } \\
\text { - Backward }\end{array}$ & $\begin{array}{l}23(2.94) \\
12.43(1.5) \\
10.57(1.99)\end{array}$ & $\begin{array}{l}19.5(2.45) \\
10.19(1.68) \\
9.31(1.54)\end{array}$ & $\begin{array}{l}3.5[1.45,5.55] \\
2.24[1.05,3.43] \\
1.26[-0.09,2.61]\end{array}$ & $\begin{array}{l}\mathrm{t}(25.5)=3.52 \\
\mathrm{t}(28)=3.85 \\
\mathrm{t}(24.4)=1.92\end{array}$ & $\begin{array}{l}\mathbf{0 . 0 0 2} \\
\mathbf{0 . 0 0 1} \\
0.07\end{array}$ & $\begin{array}{l}1.27[0.47,2.07] \\
1.36[0.55,2.17] \\
0.7[-0.06,1.45]\end{array}$ \\
\hline $\begin{array}{l}\text { WAIS-IV Digit } \\
\text { Span }^{\mathrm{a}} \\
\quad \text { - Total } \\
\text { - Forward } \\
\text { - Backward } \\
\text { - Sequencing }\end{array}$ & $\begin{array}{l}32.75(5.5) \\
11.67(2.46) \\
10.25(2.7) \\
10.83(1.8) \\
\end{array}$ & $\begin{array}{l}28.25(5.17) \\
9.75(2.52) \\
8.69(2.09) \\
9.81(1.56) \\
\end{array}$ & $\begin{array}{l}4.5[0.27,8.73] \\
1.92[-0.04,3.88] \\
1.56[-0.39,3.52] \\
1.02[-0.33,2.37]\end{array}$ & $\begin{array}{l}\mathrm{t}(23)=2.2 \\
\mathrm{t}(24.1)=2.02 \\
\mathrm{t}(20.1)=1.67 \\
\mathrm{t}(21.8)=1.57\end{array}$ & $\begin{array}{l}\mathbf{0 . 0 4} \\
0.06 \\
0.11 \\
0.13 \\
\end{array}$ & $\begin{array}{l}0.82[0.03,1.62] \\
0.75[-0.04,1.53] \\
0.64[-0.14,1.42] \\
0.6[-0.18,1.37] \\
\end{array}$ \\
\hline $\begin{array}{l}\text { WAIS-IV } \\
\text { Visual Puzzles }\end{array}$ & $18.5(3.88)$ & $19.5(3.01)$ & $-1.00[-3.64,1.64]$ & $\mathrm{t}(24.4)=-0.78$ & 0.44 & $-0.28[-1.02,0.45]$ \\
\hline $\begin{array}{l}\text { D-KEFS } \\
\text { Towers }{ }^{\text {b }} \\
\text { - Total } \\
\text { - Accuracy } \\
\text { Ratio } \\
\end{array}$ & $\begin{array}{l}20.15(4.32) \\
1.49(0.29)\end{array}$ & $\begin{array}{l}18.44(4.32) \\
2(1.04)\end{array}$ & $\begin{array}{l}1.71[-1.6,5.03] \\
-0.51[-1.08,0.06]\end{array}$ & $\begin{array}{l}\mathrm{t}(25.8)=1.06 \\
\mathrm{t}(17.9)=-1.86\end{array}$ & $\begin{array}{l}0.30 \\
0.08\end{array}$ & $\begin{array}{l}0.39[-0.37,1.14] \\
-0.62[-1.38,0.15]\end{array}$ \\
\hline $\begin{array}{l}\text { D-KEFS Color- } \\
\text { Word } \\
\quad \text { - Inhibition } \\
\text { - Flexibility }\end{array}$ & $\begin{array}{l}43.67(5.58) \\
51.42(6.97)\end{array}$ & $\begin{array}{l}45.94(7.35) \\
52.25(5.7) \\
\end{array}$ & $\begin{array}{l}-2.27[-7.3,2.75] \\
-0.83[-5.96,4.3]\end{array}$ & $\begin{array}{l}\mathrm{t}(26)=-0.93 \\
\mathrm{t}(20.9)=-0.34\end{array}$ & $\begin{array}{l}0.36 \\
0.74\end{array}$ & $\begin{array}{l}-0.33[-1.1,0.44] \\
-0.13[-0.89,0.63]\end{array}$ \\
\hline $\begin{array}{l}\text { Grooved } \\
\text { Pegboard } \\
\quad-\mathrm{DH} \\
\quad-\mathrm{NDH}\end{array}$ & $\begin{array}{l}69.73(11.26) \\
71.58(13.95)\end{array}$ & $\begin{array}{l}64.1(10.68) \\
66.12(9.65)\end{array}$ & $\begin{array}{l}5.63[-2.62,13.89] \\
5.46[-3.73,14.66]\end{array}$ & $\begin{array}{l}t(27)=1.4 \\
t(22.7)=1.23\end{array}$ & $\begin{array}{l}0.17 \\
0.23\end{array}$ & $\begin{array}{l}0.5[-0.24,1.24] \\
0.45[-0.29,1.19]\end{array}$ \\
\hline
\end{tabular}

Means anB standard deviations (SD) of the raw scores of neuropsychological tests for Professional and Amateur video gamer participanth. a, b.: $\mathrm{n}=12,13$ in the Professional group. WAIS = Weschler Adult Intelligence Scale (IV), WMS $=$ Weschler Memory Scale (III) $5 \mathrm{TN}=$ total number of items processed, $\mathrm{TN}-\mathrm{E}=$ total number of items processed minus the errors, $\mathrm{E} \%=$ percentage of errors, $\mathrm{CP}=$ condentration performance, $\mathrm{FR}=$ fluctuation rate (difference between the line with the minimum and maximum number of items processed). $\mathrm{DH}=$ Dominant hand, $\mathrm{NDH}=$ Non-dominant hand. Bolded $\mathrm{p}$-values are $<$ an alpha level of 0.05 (uncorrected). 
Figure 4

Bivariate Spearman's correlations

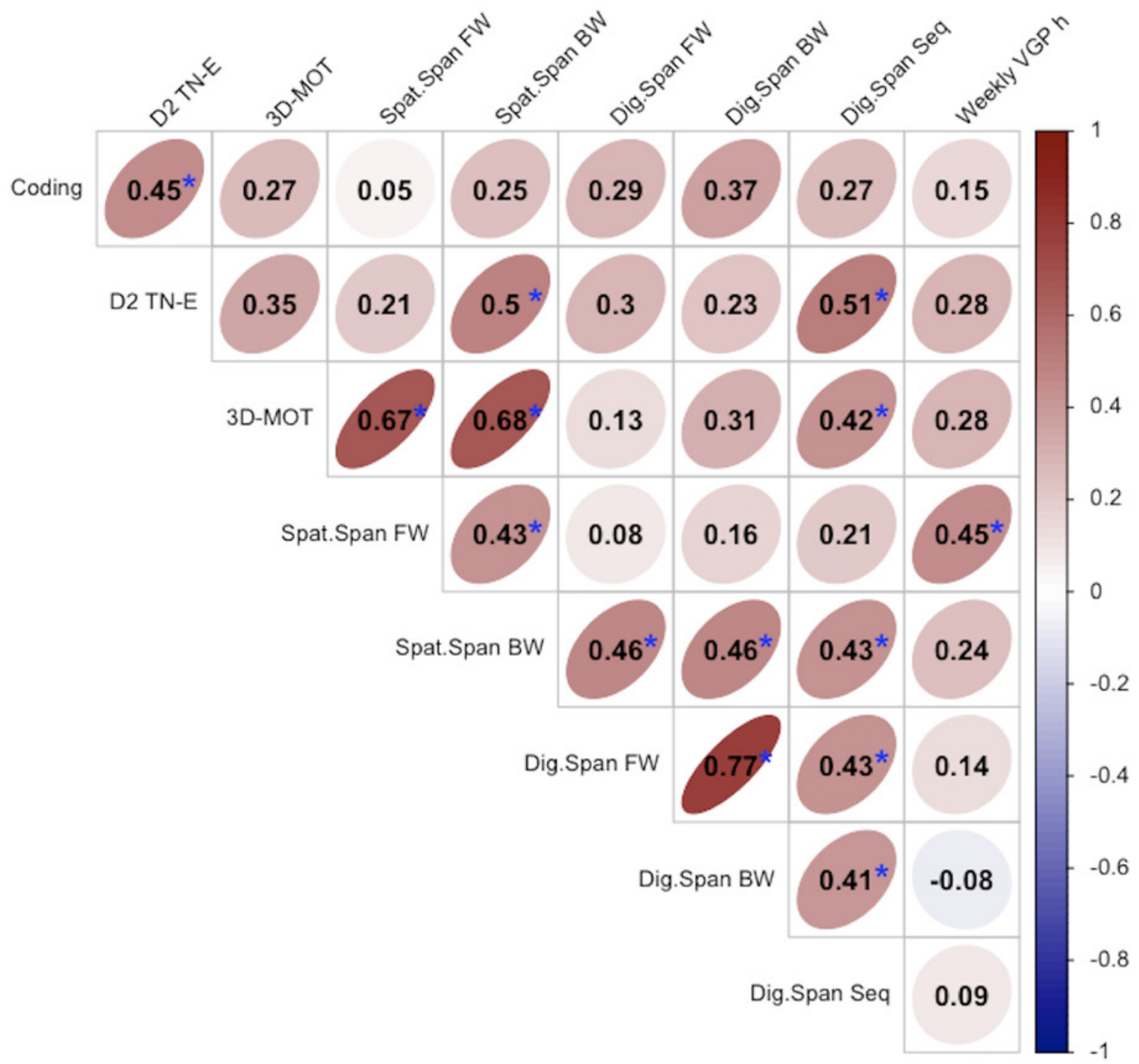


Table 3 (on next page)

Neuropsychological assessments 


\section{Table 2. Neuropsychological assessments}

\begin{tabular}{ll}
\hline D2 - Test of attention & Selective attention, sustained attention, concentration \\
\hline WMS-III -Spatial Span & Visual short-term and working memory \\
\hline WAIS-IV - Visual Puzzles & Perceptual reasoning and perceptual manipulation \\
WAIS-IV - Coding & Speed of processing \\
WAIS-IV - Digit Span & Auditory short-term and working memory \\
D-KEFS - Towers & Executive function, planning \\
D-KEFS - Color-Word & Executive function, inhibition and task switching \\
Interference & \\
Grooved Pegboard & Eye-hand coordination, dexterity
\end{tabular}

2 


\section{Table 4 (on next page)}

Results of the linear mixed effects model fit to speed thresholds in the 3D-MOT task

The proportion of the variance explained by fixed and random factors, conditional $R^{2}$, is 0.68 ; the proportion of the variance explained by the fixed factors alone, marginal $R^{2}$, is 0.29 . 
2 Table 5: Results of the linear mixed effects model fit to speed thresholds in the 3D-MOT task.

\begin{tabular}{|l|l|l|l|l|l|l|l|}
\hline Fixed Effect & $\boldsymbol{\beta}$ & $\mathbf{9 5 \% C I}$ & $\boldsymbol{t}(\mathbf{d f})$ & $\boldsymbol{p}$ & Random effect & St. Dev. & Corr \\
\hline Intercept & 0.59 & {$[0.42,0.76]$} & $t(25.8)=6.72$ & $<0.001$ & Subj Intercept & 0.24 & \\
\hline Group & 0.28 & {$[0.05,0.52]$} & $t(24.8)=2.35$ & 0.03 & Subj log2(block) & 0.10 & 0.06 \\
& & & & & & & \\
\hline $\log 2$ (block) & 0.15 & {$[0.13,0.29]$} & $t(26.1)=5.21$ & $<0.001$ & Residual & 0.28 & \\
\hline Group : $\log$ 2(block) & 0.06 & {$[-0.05,0.17]$} & $t(24.8)=1.10$ & 0.28 & & & \\
\hline
\end{tabular}

3 The proportion of the variance explained by fixed and random factors, conditional $R^{2}$, is 0.68 ; the proportion of the 4 variance explained by the fixed factors alone, marginal $R^{2}$, is 0.29 .

5

6

7

8

9

10 


\section{Table 5 (on next page)}

Standardized coefficient, Structure Coefficients, and Groups Centroids.

WAIS $=$ Weschler Adult Intelligence Scale (IV), WMS = Weschler Memory Scale (III), D-KEDS = Deli-Kaplan Executive Function System, TN = total number of items processed, of errors 
1

2 Table 4. Standardized coefficient, Structure Coefficients, and Groups Centroids.

\begin{tabular}{lccc}
\hline \multicolumn{1}{c}{ Outcome variable } & Standardized coefficient & $\mathrm{r}_{\mathrm{s}}$ & $\mathrm{r}_{\mathrm{s}}{ }^{2}$ \\
\hline WAIS-IV - Digit Span Total & -0.15 & -0.59 & 0.35 \\
WMS-III - Spatial Span Total & -0.79 & -0.79 & 0.62 \\
D-KEFS - Tower Total Score & -0.25 & -0.32 & 0.10 \\
WAIS-IV - Visual Puzzles & 0.39 & 0.24 & 0.06 \\
D-KEFS - Color word - Inhibition & 0.02 & 0.26 & 0.07 \\
D2 - TN & -0.28 & -0.61 & 0.37 \\
WAIS-IV - Coding & -0.12 & -0.35 & 0.12 \\
Grooved Pegboard - Dominant Hand & -0.37 & -0.27 & 0.07 \\
\hline Group & Centroids [95\% CI] & Cohen's d [95\% CI] & \\
\hline Professional & $-1.1[-1.68,-0.524]$ & $-1.84[-2.82,-0.83]$ & \\
Amateur & $0.76[0.275,1.25]$ & & \\
\hline
\end{tabular}

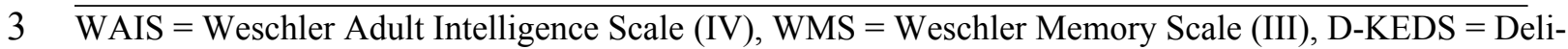

4 Kaplan Executive Function System, TN = total number of items processed, of errors 